\title{
HIV-1 incidence and HIV-1 associated mortality in a cohort of urban factory workers in Tanzania
}

\author{
M W Borgdorff, L R Barongo, A H Klokke, J N Newell, K P Senkoro, J P Velema, \\ R M Gabone
}

\begin{abstract}
Objective-To determine HIV-1 incidence and HIV-1 associated mortality in a prospective cohort study. To determine whether the cohort is suitable for studies aiming to determine the impact of interventions on HIV-1 incidence.

Methods-The study population was a cohort of 1772 urban factory workers (1478 men and 294 women) in northwest Tanzania. The study took place from October 1991 to September 1993. Outcome measures were HIV-1 seroconversion and death.

Results-HIV-1 incidence was $1 \cdot 2(95 \%$ CI $0 \cdot 7-2 \cdot 0$ ) per 100 person-years (pyr). Crude annual mortality was 4.9 per 100 pyr in those with and 0.3 in those without HIV-1 infection, giving an age and sex adjusted mortality ratio of $12.9(95 \% \mathrm{CI}$ $5 \cdot 4-30 \cdot 7)$. Of all deaths, $62 \%$ were attributable to HIV-1 infection.

Conclusion-HIV-1 infection was a major public health problem, being the major cause of death in this adult population. At an HIV-1 incidence of 1.2 per 100 pyr, a large cohort size would be required to evaluate the impact of interventions on HIV-1 incidence.
\end{abstract}

(Genitourin Med 1995;71:212-215)

National Institute for Medical Research, Mwanza, Tanzania L R Barongo

J N Newell

K P Senkoro

R M Gabone

Bugando Medical

Centre, Mwanza,

Tanzania

A Klokke

Royal Tropical

Institute, Amsterdam,
The Netherlands

$M$ W Borgdorff

Nijmegen Institute for

International Health,

Nijmegen University,

Nijmegen, The

Netherlands

J P Velema

Correspondence to: Dr M W Borgdorff,

National Institute of Public

Health and Environmental

Protection, Centre for

Infectious Disease

Epidemiology (CIE), P O

Box 1, 3720 BA Bilthoven

The Netherlands

Accepted for publication

1 April 1995
Keywords: cohort; incidence; HIV-1; mortality; Tanzania

\section{Introduction}

Measuring the incidence of HIV infection is necessary to determine the rate of HIV transmission. In addition, when studies are planned to evaluate the efficacy of interventions to reduce HIV transmission, for instance through condom promotion, control of sexually transmitted diseases (STDs) or in future through immunisation against HIV-1, a reasonable estimate of the incidence of HIV infection is required for the determination of the size of the sample needed for the study. ${ }^{1}$ However, there is limited information on the incidence of HIV-1 infection in Africa, ${ }^{2}{ }^{15}$ probably because incidence can only be measured in longitudinal studies which are difficult and costly to perform. ${ }^{16}$

HIV-1 infection has been shown to contribute substantially to mortality in hospitals in Africa. ${ }^{17-23}$ An obvious limitation of these studies is their selection bias, as in Africa many people die at home. Evidence from population-based studies is starting to emerge: in
Rwanda and Uganda HIV-1 associated mortality was shown to be substantial. 152425 Quantification of HIV-1-associated mortality is important for assessment and prediction of the demographic and socio-economic impact of the epidemic. ${ }^{26-28}$

A cohort study among urban factory workers in Mwanza, Tanzania, was started in October 1991 in order to determine the incidence of and risk factors for HIV-1 infection and other STDs, describe changes in sexual high risk behaviour following an intervention, and describe the natural history of HIV-1 infection. The prevalence of and risk factors for HIV-1 infection at intake of the cohort were found to be similar to those in the general urban population ${ }^{29}{ }^{30}$ and risk behaviour was found to be common: having multiple sexual partners in the past month was reported by $22 \%$ of male and $5 \%$ of female workers, while condoms were used by $3 \%$ only. ${ }^{31}$

In this paper we describe the HIV-1 incidence and HIV-1 associated mortality in this cohort from October 1991 to September 1993.

\section{Methods}

Study population

The study population comprised workers at a large urban factory with a work force of 2038 workers (1706 men, 332 women). Enrolment started in October 1991 and continued throughout, both for new employees and those initially declining to participate. A study clinic was created at the factory to supplement an existing clinic, as the latter was too small to cope with additional activities. The study population was advised that the aim of the study was to determine the health status of the workers, with special interest in sexually transmitted diseases and HIV-1 infection and they were invited to present themselves for registration at the study clinic, on a voluntary basis. The study was in accordance with national guidelines on HIV testing and was approved by the ethical committee of the National Institute for Medical Research. The data presented here cover a study period of two years, from 1 October 1991 to 30 September 1993.

\section{Data collection techniques}

All respondents were interviewed, physically examined and underwent laboratory investigations at intake and at four-monthly intervals thereafter. Free medical treatment was provided to all study participants at intake, 
follow-up visits, and any time they presented in between. Where necessary, patients were referred to hospital for further investigation or treatment.

The interview took place in a private room for 30 to 45 minutes in Kiswahili by trained interviewers, using a structured and precoded questionnaire. Assistant medical officers carried out the physical examination, using a pre-coded form. In the study clinic laboratory $10 \mathrm{ml}$ of venous blood was taken. Serological testing for HIV-1 antibodies took place in the reference laboratory of the zonal hospital with the Vironostika anti-HTLV-III ELISA (Organon, Boxtel, The Netherlands). All reactive and weakly reactive samples were tested with Western Blot (Organon, Epitope, Beaverton, Oregon, USA). The Western Blot was considered positive if at least two of the gp41, gp120, and gp160 bands were present. $^{32}$

A random sample of $10 \%$ of sera was retested on ELISA for internal quality control. Western Blot band readings were recorded individually and strips were kept for inspection. All sera of individuals who were not HIV-1 positive or negative throughout the study period were tested by Western Blot as well. No sero-retroconversions (from HIV-1 positive to HIV-1 negative) were observed. Comparison of 200 serology results in 1991 at the zonal laboratory with those of Nijmegen University showed a $100 \%$ agreement.

Pre- and post-HIV-1-test counselling was offered to all. After pre-test counselling a separate blood sample was taken for HIV-1 testing from those wishing to know their HIV-1 test result. The HIV-1 results were made known to the counsellor and through the counsellor to the individual concerned only. Other staff at the factory clinic were blind to the HIV-1 status of individuals.

Deaths among study participants were identified by a follow-up worker tracing nonattenders and through the welfare officer at the factory responsible for paying an allowance to the relatives of the deceased. The latter officer knew of all deaths identified, suggesting that his registration of deaths was comprehensive. The household of the deceased was visited by an assistant medical officer two to six months after death to interview the person who had taken care of the deceased before his or her death. If this per-

Table 1 Incidence of HIV-1 infection in a cohort of 1567 non-HIV-1 infected urban factory workers

\begin{tabular}{lcccc}
\hline $\begin{array}{l}\text { Age group } \\
\text { (years) }\end{array}$ & $\begin{array}{l}\text { Number } \\
\text { enrolled } \\
(\text { HIV-) }\end{array}$ & $\begin{array}{l}\text { Number of } \\
\text { of sero- } \\
\text { conversions }\end{array}$ & $\begin{array}{l}\text { Person-years } \\
\text { (pyr) of } \\
\text { follow-up }\end{array}$ & $\begin{array}{l}\text { Incidence } \\
\text { /100 pyr } \\
(95 \% \mathrm{CI})\end{array}$ \\
\hline Males & & & & \\
$15-25$ & 340 & 1 & $211 \cdot 7$ & $0 \cdot 5(0 \cdot 0-2 \cdot 6)$ \\
$25-34$ & 409 & 5 & $342 \cdot 8$ & $1 \cdot 5(0 \cdot 5-3 \cdot 4)$ \\
$35-44$ & 411 & 7 & $433 \cdot 1$ & $1 \cdot 6(0 \cdot 7-3 \cdot 3)$ \\
$45+$ & 165 & 2 & $183 \cdot 3$ & $1 \cdot 1(0 \cdot 1-3 \cdot 9)$ \\
All males & 1325 & 15 & $1171 \cdot 0$ & $1 \cdot 3(0 \cdot 7-2 \cdot 1)$ \\
Females & 105 & 0 & $64 \cdot 7$ & $0 \cdot 0(0 \cdot 0-5 \cdot 5)$ \\
$15-25$ & 97 & 2 & $84 \cdot 3$ & $2 \cdot 4(0 \cdot 3-8 \cdot 3)$ \\
$25-34$ & 31 & 0 & $38 \cdot 0$ & $0 \cdot 0(0 \cdot 0-9 \cdot 3)$ \\
$35-44$ & 9 & 0 & $8 \cdot 0$ & $0 \cdot 0(0 \cdot 0-36 \cdot 9)$ \\
$45+$ & 242 & 2 & $195 \cdot 0$ & $1 \cdot 0(0 \cdot 1-3 \cdot 7)$ \\
All females & 1567 & 17 & $1365 \cdot 9$ & $1 \cdot 2(0 \cdot 7-2 \cdot 0)$ \\
Total & & & &
\end{tabular}

son was not available the household would be visited again up to a total of three visits. Data collection tools used were open-ended questions, a structured questionnaire, and a death notification form if available. For those who died in hospital, hospital records were traced in order to get the hospital diagnosis. The probable cause of death was determined from hospital records if available and otherwise by consensus of a group of three medical officers, including one specialist in internal medicine, blinded to HIV-1 status of the deceased.

\section{Data analysis}

Two sets of person-years of follow-up were calculated. For $H I V-1$ incidence follow-up included the time period between the first and last negative HIV-1 test result plus for seroconverters half the time period between the last negative and first positive HIV-1 result. For mortality the follow-up period included the time from the first HIV-1 result until the end of follow-up; the end of follow-up was defined as the date of: (1) death or leaving the factory, (2) one year after the last HIV-1 result or (3) 30 September 1993, whichever came first. Deaths were included if they occurred inside the defined follow-up period.

The population attributable risk was calculated as the difference of the mortality rate in the total population and the mortality rate in those without HIV-1 infection and the population aetiological fraction as the ratio of the population attributable risk and the mortality rate in the total population.

\section{Results}

Of the 2038 factory workers $1478 / 1706$ (87\%) men and $294 / 332(89 \%)$ women had enrolled in the study. A total of $471(27 \%)$ of these were lost to follow-up by the end of the study period. Defaulting was not associated with sex or HIV-1 infection (data not shown), but was higher in those aged below 35 years $(317 / 1079=29 \%)$ than in those aged 35 years and over $(154 / 693=22 \%)\left(\chi^{2} 10 \cdot 7 ; p<\right.$ $0.01)$. The rate of defaulting was not associated with the time of enrolment: in the two groups enrolling before and after 26 weeks the rate was 19 per 100 person-years of follow-up.

At intake $153 / 1478(10.4 \%)$ men and $52 / 294(17 \cdot 7 \%)$ women were HIV-1 infected. In the study period 17 seroconversions took place in 1365.9 person years of follow-up giving an HIV-1 incidence rate of 1.2 per 100 person-years of follow-up (95\% CI $0 \cdot 7-2 \cdot 0)$. No association was found between seroconversion and age or sex; the power of the study to detect such associations was limited as the number of seroconversions was small (table 1).

The crude annual mortality rate was 4.9 per 100 person-years in those with and 0.3 in those without HIV-1 infection (table 2). The age and sex adjusted mortality ratio was 12.9 $(95 \%$ CI 5.4-30.7). The age and sex adjusted population attributable risk was 0.5 per 100 person-years, and the population etiological fraction $62 \%$.

Of the $14 \mathrm{HIV}-1$ infected people who died, 
Table 2 Mortality rates in an urban factory in 205 workers with and 1567 workers without HIV-1 infection

\begin{tabular}{|c|c|c|c|c|c|c|c|c|c|c|}
\hline \multirow[b]{2}{*}{$\begin{array}{l}\text { Age group } \\
\text { (years) }\end{array}$} & \multicolumn{5}{|c|}{$H I V-1$ infected } & \multicolumn{5}{|c|}{ Non-HIV-1 infected } \\
\hline & $\begin{array}{l}\text { Number* } \\
\text { Enrolled }\end{array}$ & Died & $\begin{array}{l}\text { Person- } \\
\text { years of } \\
\text { follow-up }\end{array}$ & $\begin{array}{l}\text { Mortality } \\
\text { rate } \\
(/ 100 \text { pyr) }\end{array}$ & $(95 \% C I)$ & $\begin{array}{l}\text { Number* } \\
\text { Enrolled }\end{array}$ & Died & $\begin{array}{l}\text { Person- } \\
\text { years of } \\
\text { follow-up }\end{array}$ & $\begin{array}{l}\text { Mortality } \\
\text { rate } \\
(/ 100 \text { pyr) }\end{array}$ & $95 \% C I$ \\
\hline \multicolumn{11}{|l|}{ Males } \\
\hline $15-24$ & 17 & 0 & $21 \cdot 2$ & 0.0 & $(0 \cdot 0-17 \cdot 4)$ & 340 & 1 & $421 \cdot 8$ & $0 \cdot 2$ & $(0 \cdot 0-1 \cdot 3)$ \\
\hline $25-34$ & 71 & 3 & $100 \cdot 8$ & $3 \cdot 0$ & $(0 \cdot 6-9 \cdot 2)$ & 409 & 0 & $561 \cdot 8$ & 0.0 & $(0 \cdot 0-0 \cdot 0)$ \\
\hline $35-44$ & 54 & 9 & $78 \cdot 8$ & $11 \cdot 4$ & $(5 \cdot 5-21 \cdot 4)$ & 411 & 2 & $629 \cdot 2$ & $0 \cdot 3$ & $(0 \cdot 0-1 \cdot 1)$ \\
\hline $45+$ & 11 & 1 & $12 \cdot 7$ & $7 \cdot 9$ & $(0.6-43 \cdot 3)$ & 165 & 1 & $257 \cdot 9$ & 0.4 & $(0 \cdot 0-2 \cdot 1)$ \\
\hline All males & 153 & 13 & $213 \cdot 6$ & $6 \cdot 1$ & $(3 \cdot 1-10 \cdot 4)$ & 1325 & 4 & $1870 \cdot 7$ & $0 \cdot 2$ & $(0 \cdot 1-0 \cdot 5)$ \\
\hline $\begin{array}{l}\text { Females } \\
15-24\end{array}$ & 14 & 0 & $17 \cdot 8$ & 0.0 & $(0 \cdot 0-20 \cdot 7)$ & 105 & 0 & $132 \cdot 1$ & 0.0 & $(0 \cdot 0-2 \cdot 8)$ \\
\hline $25-34$ & 26 & 0 & $35 \cdot 1$ & 0.0 & $(0.0-10.5)$ & 97 & 3 & $131 \cdot 1$ & $2 \cdot 3$ & $(0 \cdot 0-2 \cdot 6)$ \\
\hline $35-44$ & 11 & 1 & $17 \cdot 0$ & $5 \cdot 9$ & $(0 \cdot 6-32 \cdot 3)$ & 31 & 0 & $51 \cdot 1$ & $0 \cdot 0$ & $(0 \cdot 0-7 \cdot 0)$ \\
\hline $45+$ & 1 & 0 & 1.9 & $0 \cdot 0$ & $(0 \cdot 0-84 \cdot 2)$ & 9 & 0 & $13 \cdot 3$ & $0 \cdot 0$ & $(0 \cdot 0-24 \cdot 7)$ \\
\hline All females & 52 & 1 & $71 \cdot 9$ & $1 \cdot 4$ & $(0 \cdot 1-7 \cdot 8)$ & 242 & 3 & $327 \cdot 5$ & 0.9 & $(0 \cdot 2-2 \cdot 7)$ \\
\hline Total & 205 & 14 & $285 \cdot 5$ & $4 \cdot 9$ & $(2 \cdot 6-8 \cdot 2)$ & 1567 & 7 & $2198 \cdot 2$ & $0 \cdot 3$ & $(0 \cdot 1-0 \cdot 7)$ \\
\hline
\end{tabular}

^HIV-1 status is given at enrolment. Seroconverters contribute person-years of follow-up to the groups without and with HIV-1 infection before and after seroconversion, respectively.

nine met the criteria of the 1987 revised CDC/WHO AIDS case definition ${ }^{33}$ : one had cryptococcal meningitis and eight HIV wasting syndrome. Two others had had weight loss and fever, but the evidence was inadequate to make or reject the diagnosis of AIDS. The remaining three without an AIDS diagnosis had pulmonary tuberculosis, diarrhoea and pyomyositis, respectively.

\section{Discussion}

In this cohort of urban factory workers with a prevalence of HIV-1 infection of $12 \%$, the annual HIV-1 incidence rate was $1 \cdot 2 \%$. It is striking that at an HIV-1 prevalence of $12 \%$, $62 \%$ of deaths in adults were attributable to HIV-1 infection, making it one of the most important public health problems in this urban, adult population.

The incidence rate of HIV-1 infection in this study was similar to that in a cohort of urban health workers in Zaire, ${ }^{34}$ and rural population cohorts in Uganda, ${ }^{14} 15$ but much lower than that of $4.7 \%$ in an urban population in a neighbouring Region in Tanzania, ${ }^{11}$ which also had a much higher HIV-1 prevalence (of $24 \%$ ) at the start of the study period. Urban women of childbearing age in Rwanda and Zambia also had higher incidence rates of $3-4 \% .{ }^{6934}$ As might be expected, the observed HIV-1 incidence was much lower than that of high risk groups in Africa such as spouses of HIV-1 infected people, ${ }^{710}$ prostitutes $^{812}{ }^{13}$ and attenders of sexually transmitted disease clinics. ${ }^{5}$ Low HIV-1 incidence rates of approximately $2 \%^{35}$ and of $1 \cdot 1 \%^{36}$ were observed in prostitutes in low prevalence areas, though in the latter study a rapid increase in incidence rates over time was noted. ${ }^{36}$

Mortality rates in those with and without HIV-1 infection were similar to those reported from Rwanda, ${ }^{25}$ while the population aetiological fraction in the present study of $62 \%$ was lower than that in Rwanda $(90 \%)$, which is explained by the difference in HIV-1 prevalence $(32 \%$ in Rwanda and $12 \%$ in the present study). In Uganda, mortality rates were approximately twice as high, both in those with and without HIV-1 infection, ${ }^{1524}$ resulting in a population aetiological fraction of $48 \%$ at an HIV-1 prevalence of $8 \%{ }^{15}$

The population attributable risk is determined not only by the prevalence of the risk factor (HIV-1 infection) but also by the relative risk or mortality rate ratio. As might be expected, the mortality rate ratios in these three studies were not significantly different: they were reported to be 20.8 in Uganda and 12.9 in the present study, and can be estimated at approximately 28 in Rwanda. Confidence intervals are particularly wide in the present and the Rwanda study, because of the small numbers of deaths in non-HIV-1infected people.

It seems likely that a sizeable proportion of deaths (at least $3 / 14=21 \%$ ) occurred in HIV1 infected people who had not yet developed AIDS, as was shown in Rwanda, ${ }^{9}$ Kenya, ${ }^{19}$ and among intravenous drug users in the U.S., ${ }^{37-39}$ although because of data limitations a precise estimate of this proportion could not be made. Tuberculosis was diagnosed in 2 out of 14 deaths; an autopsy study in Ivory Coast $^{40}$ suggests that a much larger proportion of deaths in the study population may have been attributable to tuberculosis than is evident from our data.

The study has a number of limitations. Although total enrolment was reasonable at $87 \%$ of those eligible, losses to follow-up were considerable at 19 per 100 person-years of follow-up. These losses to follow-up were largely due to two factors: many study participants did not like to submit blood samples repeatedly, and owing to economic difficulties the factory had to close down temporarily in the second year of the study, sending staff on unpaid leave. The first factor might be partly overcome by more intensive follow-up and education; the latter factor however, which affected in particular those in younger age groups, is much more serious, and may if repeated jeopardise the continuation of this cohort study.

The effect of these losses to follow-up may be an underestimate of the incidence of HIV-1 infection, if the incidence is highest in those less than 35 years old. ${ }^{14}$ The effect on the mortality results is probably limited, as families of those sent on unpaid leave still qualified for receiving an allowance if a worker died. 
For studies aiming to show that preventive interventions reduce the incidence of HIV-1 infection, a large sample size will be required to show an effect at a baseline incidence of $1 \cdot 2 \%$. For instance, if a vaccine against HIV-1 reduced the incidence of HIV-1 infection by $50 \%$ from 1.2 to 0.6 per 100 pyr, a sample size would be required in intervention and control group of approximately 5500 pyr each to have a $90 \%$ probability of showing that the vaccine is effective.

In conclusion, HIV-1 infection was a major public health problem, being the major cause of death in this adult population. At an HIV-1 incidence of 1.2 per 100 pyr, a large cohort size would be required to evaluate the impact of interventions on HIV-1 incidence.

We thank the Principal Secretary, Ministry of Health and the Director General, National Institute for Medical Research for permission to carry out the study and to publish its results. We are grateful to Prof A S Muller, Prof R A Coutinho, and Dr J T Boerma for their critical comments on drafts of this paper. The research for this publication was financed by the Netherlands' Minister for Development Cooperation, Section for Research and Technology, P.O. Box 20061, 2500 EB, The Hague, as part of the Tanzania-Netherlands Research Project on AIDS part of the Tanzania-Netherlands Research Project on AIDS
and HIV Infection in Mwanza Region. Responsibility for the contents and for the opinions expressed rests solely with the authors; publication does not constitute an endorsement by the Netherlands' Minister for Development Co-operation.

1 Dixon DO, Rida WN, Fast PE, Hoth DF. HIV vaccine trials: some design issues including sample size calculation. $\mathcal{F}$ Acquir Immune Defic Syndr 1993;6:485-96.

2 Nkowane BJ. Prevalence and incidence of HIV infection in Africa: a review of data published in 1990. AIDS 1991;5(Suppl 1):S7-S15.

3 Mann JM, Francis H, Quinn TC, et al. HIV seroincidence in a hospital worker population. Ann Soc Belg Med Trop 1986;66:245-50.

4 N'galy B, Ryder RW, Bila K, et al. Human immunodeficiency virus infection among employees in an African hospital. N Engl f Med 1988;319:1123-7.

5 Cameron DW, Simonsen JN, D'Costa LJ, et al. Female to male transmission of human immunodeficiency virus type 1: risk factors for seroconversion in men. Lancet 1989;ii:403-7.

6 Hira SK, Mangrola SG, Mwale C, et al. Apparent vertical transmission of human immunodeficiency virus type 1 by breastfeeding in Zambia. 7 Pediatr 1990;117:421-4.

7 Kamenga M, Ryder RW, Jingu M, et al. Evidence of marked sexual behaviour change associated with low HIV-1 seroconversion in 149 married couples with discordant HIV-1 serostatus: experience at an HIV counselling center in Zaire. AIDS 1991;5:61-7.

8 Plummer FA, Simonsen JN, Cameron DW, et al. Cofactors in male-female sexual transmission of human immunodeficiency virus type 1 . F Infect $D$ is 1991;163:233-9.

9 Allen S, Serufilira A, Bogaerts J, et al. Confidential HIV testing and condom promotion in Africa. $¥ A M A 1992$; 268:3338-43.

10 Allen S, Tice J, Perre P van de, et al. Effect of serotesting with counselling on condom use and seroconversion among HIV discordant couples in Africa. BMF 1992; 304:1605-9.

11 Killewo JZJ, Sandstrom A, Bredberg Raden U, Mhalu FS, Biberfeld G, Wall S. Incidence of HIV-1 infection among adults in the Kagera Region of Tanzania. Int $\mathcal{J}$ Epidemiol 1993;22:528-36.

12 Laga M, Manoka A, Kivuvu M, et al. Non-ulcerative sexually transmitted diseases as risk factors for HIV-1 transmission in women: results from a cohort study. AIDS 1993;7:95-102.

13 Zekeng L, Feldblum PJ, Oliver RM, Kaptue L. Barrier contraceptive use and HIV infection among high-risk women in Cameroon. AIDS 1993;7:725-31.

14 Wawer MJ, Sewankambo NK, Berkley S, et al. Incidence of HIV-1 infection in a rural region of Uganda. $B M \mathcal{F}$ 1994;308:171-3.
15 Mulder DW, Nunn AJ, Wagner HU, Kamali A, KengeyaKayondo JF. HIV-1 incidence and HIV-1-associated mortality in a rural Ugandan population cohort. AIDS 1994;8:87-92.

16 Ryder RW, Piot P. Epidemiology of HIV-1 infection in Africa. In: P Piot, JM Main eds Bailliere's Clinical Tropical Medicine and Communicable Diseases 1988;3: 13-29.

17 De Cock KM, et al. AIDS-the leading cause of death in the west African city of Abidjan, Ivory Coast. Science 1990;249:793-6.

18 De Cock KM, Porter A, Odehouri K, et al. Rapid emergence of AIDS in Abidjan, Ivory Coast. Lancet 1989; ii:408-11.

19 Gilks CF, Brindle RJ, Otieno LS, et al. Life-threatening bacteraemia in HIV-1 seropositive adults admitted to hospital in Nairobi, Kenya. Lancet 1990;336:545-9.

20 Hassig SE, Perriens J, Baende E, et al. An analysis of the economic impact of HIV infection among patients at Mama Yemo Hospital, Kinshasa, Zaire. AIDS 1990;4: 883-7.

21 Mbaga JM, Pallangyo KJ, Bakari M, Aris EA. Surviva time of patients with acquired immune deficiency syndrome: experience with 274 patients in Dar-es-Salaam drome: experience with 274 pati
East Afr Med $\mathcal{F}$ 1990;67:95-9.

22 Nelson AM, Hassig SE, Kayembe M, et al. HIV-1 seropositivity and mortality at University Hospital, Kinshasa Zaire, 1987. AIDS 1991;5:583-6.

23 Muller O, Moser R. HIV-1 disease in a Kampala hospital 1985-89 (letter) Lancet 1990;335:236-7.

24 Mulder DW, Nunn AJ, Kamali A, Nakiyingi J, Wagne HU, Kengeya-Kayondo JF. Two-year HIV-1-associated mortality in a Ugandan rural population. Lancet 1994; 343:989-90.

25 Lindan CP, Allen S, Serufilira A, et al. Predictors of mortality among HIV-infected women in Kigali, Rwanda. Ann Intern Med 1992;116:320-8.

26 Anderson RM, May RM, Boily MC, Garnett GP, Rowley JT. The spread of HIV-1 in Africa: sexual contact patterns and the predicted demographic impact of AIDS Nature 1991;352:581-9.

27 Anderson RM. Some aspects of sexual behaviour and the potential demographic impact of AIDS in developing countries. Soc Sci Med 1992;34:271-80

28 Gregson S, Garnett GP, Anderson RM. Is HIV-1 likely to become a leading cause of adult mortality in subSaharan Africa? $\mathcal{F}$ Acquir Immune Defic Syndr 1994;7: 839-52.

29 Barongo LR, Borgdorff MW, Mosha FF, et al. The epidemiology of HIV-1 infection in urban areas, roadside settlements and rural villages in Mwanza Region, settlements and rural villages

30 Barongo LR, Borgdorff MW, Newell JN, et al. Intake of a cohort study of urban factory workers in northwest Tanzania: risk factors for HIV-1 infection. Trop Geograph Med 1994;46:157-62.

31 Borgdorff MW, Barongo LR, Newell JN, et al. Sexual partner change and condom use among urban factory workers in northwest Tanzania. Genitourin Med 1994;31:378-83.

32 World Health Organization. Acquired Immune Deficiency Syndrome (AIDS)-Proposed WHO criteria for interpreting results from Western blot assays for HIV-1, HIV-2, and HTLV-L/HTLV-II. Wkly Epidemiol Rec 1990;65:281-3.

33 World Health Organization. Acquired immunodeficiency syndrome (AIDS) - 1987 revision of CDC/WHO case syndrome (AIDS) - 1987 revision of CDC/WHO case
definition for AIDS. Wkly Epidemiol Rec 1988;63:1-7.

34 Leroy V, Van de Perre P, Lepage P, et al. Seroincidence of HIV-1 infection in African women of reproductive age: a prospective cohort study in Kigali, Rwanda, 1988-1992. AIDS 1994;8:983-6.

35 Jama Ahmed H, Omar K, Yusuf Adan S, Mohamed Guled A, Grillner L, Bygdeman S. Syphilis and human immunodeficiency virus seroconversion during a 6-month follow-up of female prostitutes in Mogadishu, Somalia. Int $\mathcal{F}$ STD AIDS 1991;2:119-23.

36 Kanki PL, Travers KU, MBoup S, et al. Slower heterosexual spread of HIV-2 than HIV-1. Lancet 1994;343. ual sprea

37 Stoneburner RL, Des Jarlais DC, Benezra D, et al. A larger spectrum of severe HIV-1-related disease in intravenous drug users in New York City. Science 1988;242:916-9.

38 Selwyn PA. Injection drug use, mortality, and the AIDS epidemic. Am f Public Health 1991;81:1247-9.

39 Selwyn PA, Alcabes P, Hartel D, et al. Clinical manifestations and predictors of disease progression in drug users with human immunodeficiency virus infection. $N$ Engl $\%$ Med 1992;327:1697-703.

40 Lucas SB, Hounnou A, Peacock C, et al. The mortality and pathology of HIV infection in a West African city. AIDS 1993;7:1569-79. 